\title{
Influence of Fluorination at Position 16 of Antibacterial Pristinamycins II\#
}

\author{
Eric Bacqué*
}

Abstract: The influence of a fluorine atom at position $\mathrm{C}(16)$ of antibacterial pristinamycins II upon antibacterial, physico-chemical and pharmacokinetics properties is described.

Keywords: Antibacterial · DAST · Fluorination · Pristinamycins II

\section{Introduction}

During the last twenty years, resistance among Gram-positive organisms such as Staphylococcus aureus, the coagulase-negative staphylococci, Streptococcus pneumoniae and the enterococci has slowly evolved into a major concern for public health, especially in hospitals [1]. To face the challenge of multi-resistant Gram-positive bacteria, the streptogramin class of antibiotics constitutes a particularly attractive response. The streptogramins are naturally occurring antibiotics discovered more than forty years ago. They are indeed unique among the antibiotics in that they consist of the association of two structurally unrelated components: the group B components, such as pristinamycin I (PI), members of the macrolide-lincosamides-streptogramin $\mathrm{B}$ group (the so-called $\mathrm{MLS}_{\mathrm{B}}$ group) are cyclic depsipeptides (Fig. 1) whereas the group A components such as pristinamycin II (PII) are peptidic macrolactones (Fig. 1). The combination of two molecules, one

*Correspondence: E. Bacqué

Centre de Recherche de Paris

Aventis DI\&A France, Bat Pasteur

102 Route de Noisy

F- 93235, Romainville cedex

Tel.: +33 149915341

Fax: +33 149915087

E-Mail: eric.bacque@aventis.com.

\#This publication is dedicated to the memory of my colleague Jean-Claude Barrière.

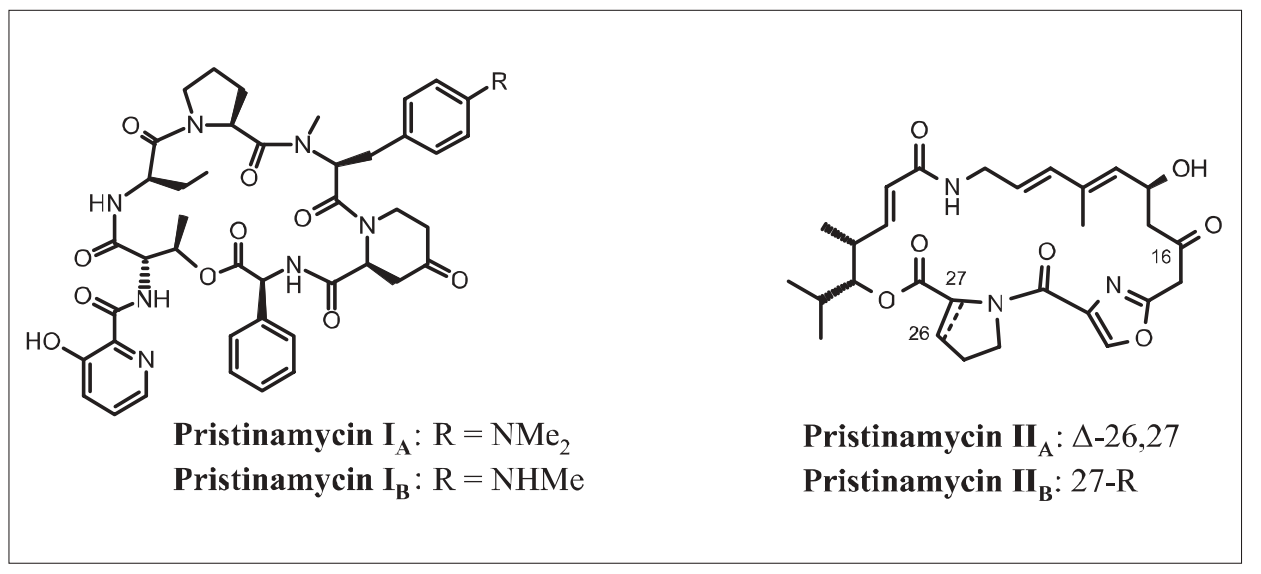

Fig. 1. Structures of representative group $A$ and group $B$ streptogramins

from each group, acts synergistically on the ribosome of bacteria, thereby inhibiting protein synthesis [2]. Streptogramins display in vitro bacteriostatic activity against most Gram-positive cocci, certain Gramnegative bacteria (such as Haemophilus), certain fastidious bacteria and Gram-positive anaerobes as well as in vitro and in vivo bactericidal activity against most of these sensitive species. They are also characterized by a long post-antibiotic effect and a very low resistance selection rate (below 1 cell in $10^{10}$ cells). As a consequence of these unique properties, the prevalence of resistant staphylococci in France is still below 5\% [3] though Pyostacine ${ }^{\circledR}$, a streptogramin made up of a mixture of pristinamycin IA and IIA as major components in a 30/70 ratio by weight, has been extensively used for more than thirty years in this country for respiratory tract infections and for skin or bone infections.

Because of the lack of water solubility of natural pristinamycins that had prevented their use for treating Gram-positive severe infections in hospital, we initiated, in the 80 s, a program of semi-synthesis aimed at discovering water-soluble antibacterial pristinamycins. These endeavors culminated with the development of Synercid ${ }^{\circledR}$ (Fig. 2 ), the first injectable streptogramin that has been approved in the US in 1999 for the treatment of severe Gram-positive infections in hospital [4-6].

After this first success, we continued our efforts to identify the next-generation oral streptogramin. With this objective in mind, we embarked upon a new program of semi-synthesis both in the PI and PII series. Regarding this latter series, we were particularly interested in introducing a fluorine atom at $\mathrm{C}(16)$. Based on the well-known bioisosteric relationship between a carbonyl (or a $\mathrm{C}-\mathrm{OH}$ bond) and a $\mathrm{C}-\mathrm{F}$ bond, we reasoned that the fluorine atom would retain similar inhibition of the target ribosome compared to natural pristinamycins II while providing an opportunity to overcome the known limitations of the pristinamycins II, namely chemical instability at acidic/basic pHs due mainly to the sensitive $\beta$-hydroxy ketone system which is very 


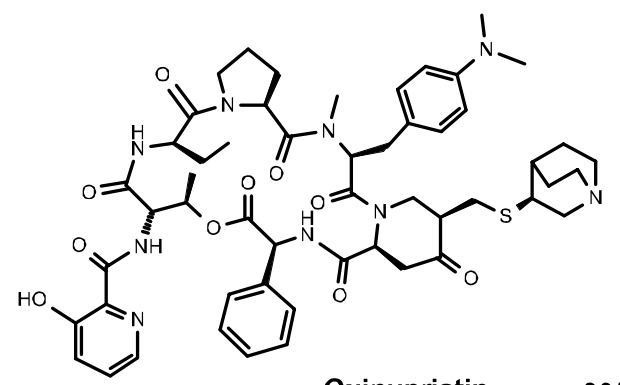

Quinupristin

$30 / 70$

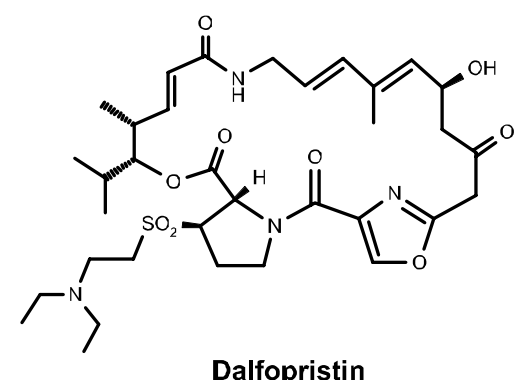

Fig. 2. Structure of the two components of Synercid ${ }^{\circledR}$

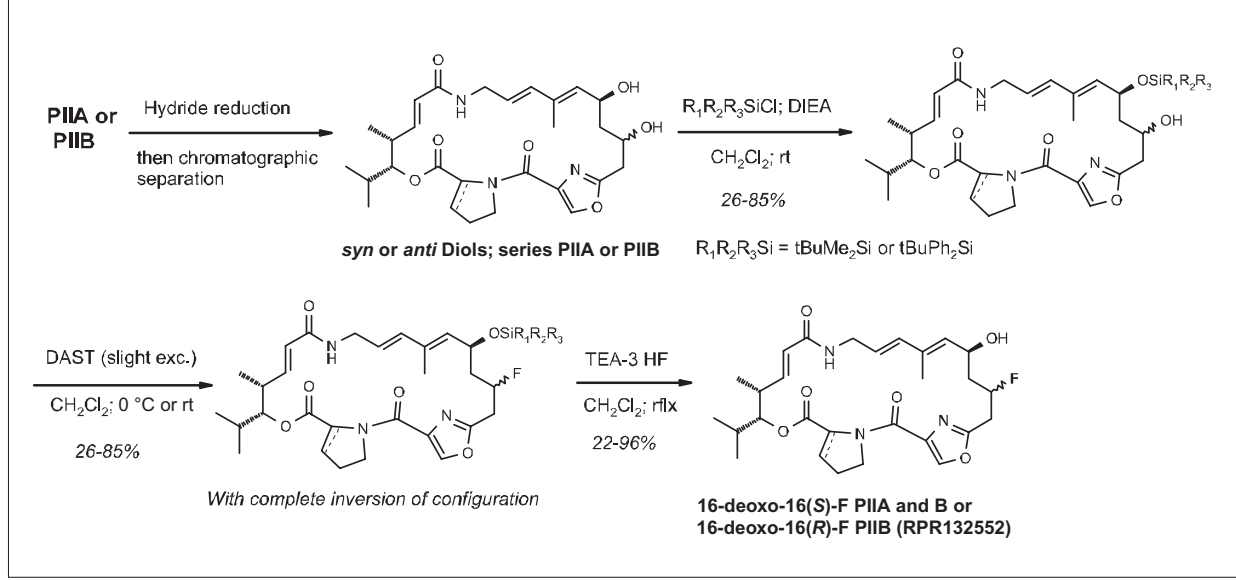

Scheme. Preparation of 16-fluoro pristinamycins II

Table 1. Comparative in vitro activities of C(16)-substituted Plls

\begin{tabular}{|c|c|c|c|c|}
\hline $\begin{array}{l}\text { 16-Substituent } \\
\text { (PII series) }\end{array}$ & $\begin{array}{l}\text { Poly(U) } \\
\left(\mathrm{IC}_{50} ;[\mu \mathrm{M})\right]\end{array}$ & $\begin{array}{l}\text { MICs (IP8203) } \\
\text { (alone; [ } \mathrm{g} / \mathrm{ml}] \text { ) }\end{array}$ & $\begin{array}{l}\text { MICs (IP8203) } \\
\text { (with PIB; [ } \mu \mathrm{g} / \mathrm{ml}] \text { ) }\end{array}$ & Synergy \\
\hline$=O(P I I A)$ & 0.2 & 2 & 0.06 & Strong \\
\hline$=O(\mathrm{PIIB})$ & 0.1 & 4 & 0.12 & Strong \\
\hline$(R)-\mathrm{OH}(\mathrm{PIIA})$ & 0.11 & 1 & 0.5 & Weak \\
\hline (S)-OH (PIIA) & $>10$ & 32 & 0.5 & Strong \\
\hline$(R)-\mathrm{OH}(\mathrm{PIIB})$ & 0.05 & 1 & 0.25 & Moderate \\
\hline (S)-OH (PIIB) & 6 & 32 & 0.5 & Strong \\
\hline$(R)-\mathrm{F}(\mathrm{PIIA})$ & 0.07 & 0.12 & 0.03 & Moderate \\
\hline (R)-F (PIIB) (RPR132552) & 0.06 & 0.25 & 0.03 & Strong \\
\hline (S)-F (PIIB) & 0.5 & 8 & 0.5 & Strong \\
\hline
\end{tabular}

prone to dehydration to generate inactive trienones, low oral absorption and poor metabolic stability resulting in poor pharmacokinetics (PK) properties. Hereafter, we report the successful preparation of 16deoxo-16-fluoro pristinamycins IIA and IIB and we discuss the impact of the 16fluoro substituent upon various properties of the naturals PIIs and of their corresponding diols such as antibacterial activities, aqueous solubility, chemical stability, ab- sorption/disposition/metabolization/excretion (ADME) properties, and pharmacokinetics parameters.

\section{Results and Discussion}

The syn and anti diols PIIs [2][7] (16deoxo-16(R)- and 16(S)-hydroxy PIIs, respectively), obtained as mixtures by simple hydride reduction of the corresponding nat- ural PIIs, were obvious precursors of the desired 16-fluoro PIIs, via a DAST-mediated substitution of the 16-hydroxy group. Because of the presence of a second hydroxy group at C(14), direct fluorination of the diols only delivered intractable mixtures. This observation prompted us to mask the 14-hydroxy group during the fluorination step by a silyl group that we had previously shown could be introduced efficiently and regioselectively while being cleavable under mild conditions by fluoride ions.

We were delighted to find that DASTfluorination of 16-deoxo-16-hydroxy-14silyloxy PIIs proceeded smoothly with complete inversion of configuration at $\mathrm{C}(16)$ to afford the corresponding 16-fluoro PIIs and that subsequent desilylation cleanly afforded the expected 16-deoxo-16fluoro PIIs. In the PIIB series, the overall yields were exceptionally high for pristinamycin II chemistry (above $80 \%$ ) whereas yields were not as good from 16(S)-PIIA diol due to a more pronounced fragility of the $16(R)$-fluoro derivative under the reaction conditions (Scheme).

All the compounds mentioned above were evaluated for their antibacterial activities: inhibition of the target ribosome as measured by the poly(U) dependent poly(Phe) synthesis test (a cell-free translation assay [8]), in vitro activity alone and in association with PIB (minimum inhibitory concentrations: MICs in $\mathrm{mg} / \mathrm{l}$ [9]), in vivo activity, in association with PIB, by the oral (po) or subcutaneous ( $s c$ ) routes, in a model of septicemia induced by a representative sensitive $S$. aureus [10]. In terms of inhibition of the ribosome (see column 2 of Table $1)$, the 16(R)-fluoro PIIs (syn isomers) displayed $\mathrm{IC}_{50} \mathrm{~S}$ similar to those of the corresponding natural PIIs and to those of the corresponding 16(R)-diols. These observations clearly demonstrated that, in the pristinamycin II series, a 16(R)-fluoro was an effective bioisosteric replacement of the 16-carbonyl group and of the 16(R)-hydroxyl group. The 16(S)-fluoro PIIB (anti isomer) was less active than the corresponding 16(R) epimer and PIIB but much more active than the $16(S)$-diol PIIB. The same influence of the stereochemistry upon target inhibition was observed in the diol series: whatever the pristinamycin A or B series, the $16(R)$ epimer was much more active than the $16(S)$ epimer.

MICs alone (PII alone; column 3 of Table 1) were roughly correlated to target inhibition: the most potent derivatives on the target also displayed the best MICs alone. However, for a similar level of ribosome inhibition, the MICs could significantly vary. For example, the two 16(R)-PII diols were much less active against bacteria than the corresponding 16(R)-fluoro PIIs. This was also the case for PIIB compared to 
Table 2. Comparative in vivo activities of $\mathrm{C}(16)$ substituted Plls

\begin{tabular}{|c|c|c|c|}
\hline $\begin{array}{l}\text { 16-Substituent } \\
\text { (PII series) }\end{array}$ & $\begin{array}{l}\text { MIC (IP8203; } \\
\text { associated to } \\
\text { PIB; }[\mu \mathrm{g} / \mathrm{ml}])\end{array}$ & $\begin{array}{l}\text { In vivo (septicemia sc; } \\
\text { S.a. IP8203; ED } \\
\text { [ } \mu \text { g/kg]; associated } \\
\text { to PIB } 30 / 70 \text { ) }\end{array}$ & $\begin{array}{l}\text { In vivo (septicemia po; } \\
\text { S.a. IP8203; ED }{ }_{50} \\
\text { [ } \mu \mathrm{g} / \mathrm{kg} \text {; } \text {; associated } \\
\text { to PIB } 30 / 70 \text { ) }\end{array}$ \\
\hline$=O(P I I A)$ & 0.06 & nd & 130 \\
\hline$=\mathrm{O}(\mathrm{PIIB})$ & 0.12 & 3 & 95 \\
\hline$(R)-\mathrm{OH}$ (PIIA) & 0.5 & 8 & 95 \\
\hline (S)-OH (PIIA) & 0.5 & 2.4 & 100 \\
\hline$(R)-\mathrm{OH}(\mathrm{PIIB})$ & 0.25 & 4 & 140 \\
\hline (S)-OH (PIIB) & 0.5 & 4.6 & 95 \\
\hline$(R)-\mathrm{F}(\mathrm{PIIA})$ & 0.03 & 9.5 & 110 \\
\hline (R)-F (PIIB) (RPR132552) & 0.03 & 5 & 40 \\
\hline (S)-F (PIIB) & 0.5 & $<1.5$ & 110 \\
\hline
\end{tabular}

Table 3. Comparative in vivo activities and ADME properties of $\mathrm{C}(16)$ substituted PIls

\begin{tabular}{|c|c|c|c|c|}
\hline Entry & 16-Substituent & $\begin{array}{l}\text { In vivo (septicemia po; } \\
\text { IP8203; ED50 [mg/kg]; } \\
\text { associated to PIB 30/70) }\end{array}$ & $\begin{array}{l}\text { Metabolic } \\
\text { Turnovera }\end{array}$ & $\begin{array}{l}\text { Caco-2 } \\
\% \text { absorbed }^{b}\end{array}$ \\
\hline 1 & $=O(P I I A)$ & 130 & $48 \%$ & 4.4 \\
\hline 2 & $=O(\mathrm{PIIB})$ & 95 & $41 \%$ & 2.3 \\
\hline 3 & $(R)-\mathrm{OH}(\mathrm{PIIA})$ & 95 & $24 \%$ & 0.7 \\
\hline 4 & (S)-OH (PIIA) & 100 & $34 \%$ & 0.07 \\
\hline 5 & $(R)-\mathrm{OH}(\mathrm{PIIB})$ & 140 & $32 \%$ & 0.7 \\
\hline 6 & (S)-OH (PIIB) & 95 & $20 \%$ & nd \\
\hline 7 & $(R)-\mathrm{F}(\mathrm{PIIA})$ & 110 & $66 \%$ & nd \\
\hline 8 & $\begin{array}{l}(R)-\mathrm{F}(\mathrm{PIIB}) \\
\text { (RPR132552) }\end{array}$ & 40 & $62 \%$ & 8 \\
\hline 9 & (S)-F (PIIB) & 110 & $30 \%$ & nd \\
\hline
\end{tabular}

a\% of compound metabolized by CD1 mouse hepatic microsomes, $5 \mu \mathrm{M}$; incubation time 20 min. b Absorption across Caco-2 monolayers apical to basal: \% of appearance in the receptor chamber after $180 \mathrm{~min}$; concentration 100 uM. nd: not determined.

the 16(R)-fluoro PIIs. These discrepancies probably reflected different capacities of these PIIs to cross the bacterial membranes. For Gram-positive bacteria, increased lipophilicity is expected to favor penetration, which would explain improved MICs for the 16-fluoro derivatives compared to the more hydrophilic diols and natural PIIs (see column 3 of Table 4 for selected $\log \mathrm{D}$ values at $\mathrm{pH}$ 7.4).

Regarding MICs in association with PIB (PIB/PII: 30/70 w/w; see column 4 of Table 1), they did not result from a direct translation of the figures of the MICs alone. The level of synergy (column 5 of Table 1) depended on the nature of the PII component and surprisingly ranged from weak to strong, from a two-fold to a 64-fold factor, whatever the level of inhibition of the ribo- some. These observations were difficult to understand on the sole basis of the published hypothesis that postulated that synergy of the streptogramin results from the increased affinity of the group B streptogramin following a conformational change of the ribosome induced by the binding of the group A streptogramin [11]. Our results suggest that complementary explanations are necessary to fully understand the phenomenon of synergy.

In vivo activities, in association with PIB (PIB/PII 30/70, w/w), were again not simply correlated to MICs (in association with PIB 30/70). By the subcutaneous route (column 3 of Table 2), all tested PIIs displayed activities in the same range ( 1 to 10 $\mathrm{mg} / \mathrm{kg}$ ), whatever the MICs of the combination PIB/PII. In particular, 16(S)-diol
PIIA and $16(S)$-fluoro PIIB were the two most potent PIIs though the less active in vitro (in combination with PIB). In contrast, the gain of potency observed in vitro for the $16(R)$-fluoro PIIs was totally lost in vivo sc. These observations were clearly linked to the metabolic stability of the PII component (see column 4 of Table 3): a good metabolic stability of the PII component was able to compensate for a moderate in vitro potency (as for the PII diols or 16(S)-fluoro PIIB) and hence afford a better in vivo sc activity than for a PII displaying in vitro potency associated to metabolic instability (as for 16(R)-fluoro PIIB).

By the oral route, in association with PIB (column 4 of Table 3), all compounds, with the notable exception of the 16(R)-fluoro PIIB (entry 8), were as active or less active than PIIB.

High in vitro potency did not ensure high in vivo potency po (see in particular the case of PIIA, PIIB and 16(R)-fluoro PIIA in entries $1,2,7)$. Understanding these figures required the cross-examination of the ADME properties (column 4 of Table 3: metabolic stability as indicated by mice microsome turnovers and column 5 of Table 3: oral absorption as evaluated by Caco- 2 absorption) and of the antibacterial properties of the PIIs. The modest antibacterial diols (entries 3 to 6 ), though metabolic stable, were poorly permeable and this could explain the modest in vivo activities by the oral route. For $16(R)$-fluoro PIIB (entry 8 of Table 3), a combination of low MICs and high absorption rate resulted in a potent association in vivo by the oral route in spite of a high metabolic turnover. These properties were not unexpected based on the physicochemical characteristics of this PII compared to those of the diols and of natural PIIs: improved oral absorption was likely to result from increased lipophilicity associated to a reasonable aqueous solubility (see columns 5-7 of entry 4 in Table 4) while increased metabolization rate could also be a consequence of the higher lipophilicity that favored recognition by cytochrome P450 3A4 which is known to metabolize some PIIs [12]. These ADME properties were confirmed by the pharmacokinetics (PK) properties of $16(R)$-fluoro PIIB (Table 5). Though still unsatisfactory (see in particular, the high clearance and following oral administration, the low systemic exposure considering the magnitude of the dose), the PK parameters of the fluoro derivative showed a significant improvement compared to PIIB. Absolute bioavailability was close to $2 \%$ compared to almost $0 \%$ for PIIB. This improvement could explain in part the better in vivo activity of 16R-fluoro PIIB compared to PIIB.

Regarding 16(S)-fluoro PIIB (entry 9 of Table 3), in vivo activity by the oral route was not in line with what we observed by 
Table 4. Comparative physico-chemical properties of $\mathrm{C}(16)$ substituted PIls

\begin{tabular}{|c|c|c|c|c|c|c|}
\hline \multirow[t]{2}{*}{ Entry } & \multirow[t]{2}{*}{ PII } & \multirow{2}{*}{$\begin{array}{l}\log D \\
\mathrm{pH} 7.4\end{array}$} & \multirow[t]{2}{*}{ Chemical stability } & \multicolumn{3}{|c|}{ Solubility $[\mu \mathrm{g} / \mathrm{ml}]$} \\
\hline & & & & pH 5 & pH 7.4 & Water \\
\hline 1 & PIIA & 1.9 & $\begin{array}{l}\text { Unstable between } \\
\mathrm{pH} \mathrm{2-4} \mathrm{and} 7-12\end{array}$ & 50 & 50 & 50 \\
\hline 2 & PIIB & 1.6 & $\begin{array}{l}\text { Unstable between } \\
\mathrm{pH} \mathrm{2-4} \mathrm{and} \mathrm{7-12}\end{array}$ & 3500 & 3500 & 3500 \\
\hline 3 & 16(R) PIIB diol & 1.5 & $\begin{array}{l}\text { Stable between } \\
\mathrm{pH} 4 \text { to } 13 \text {; unstable } \\
\text { at } \mathrm{pH} 1 \text { to } 4\end{array}$ & $>1000$ & 4500 & $>1000$ \\
\hline 4 & $\begin{array}{l}\text { 16(R)-F-PIIB } \\
\text { (RPR132552) }\end{array}$ & 2.37 & $\begin{array}{l}\text { Stable between } \\
\mathrm{pH} 4 \text { and } 9 \text {; unstable } \\
\text { at } \mathrm{pH} 2 \text { and } 12\end{array}$ & 250 & 220 & 980 \\
\hline 5 & 16(R)-F-PIIA & 2.47 & $\begin{array}{l}\text { Unstable between } \\
\mathrm{pH} 1-4 \text { and } 9-12 ; \\
\text { slight instability } \\
\text { between } \mathrm{pH} 4 \text { and } 7.5\end{array}$ & $<10$ & $<10$ & $<10$ \\
\hline
\end{tabular}

Table 5. Comparative pharmacokinetics properties of RPR132552 and PIIB

\begin{tabular}{|c|c|c|c|c|c|c|c|c|}
\hline PII & $\begin{array}{l}\text { PI Dose } \\
\text { [mg/kg] }\end{array}$ & $\begin{array}{l}C_{\max } \\
{[\mathrm{ng} / \mathrm{ml}]}\end{array}$ & $\begin{array}{l}t_{\max } \\
{[\mathrm{h}]}\end{array}$ & $\begin{array}{l}\mathbf{F} \\
{[\%]}\end{array}$ & $\begin{array}{l}\text { AUC }_{0-\infty} \\
{[\mathrm{h} . \mathrm{ng} / \mathrm{ml}]}\end{array}$ & $\begin{array}{l}\text { Terminal } \\
\mathbf{t}_{1 / 2}[\mathrm{~h}]\end{array}$ & $\begin{array}{l}\mathrm{Cl}_{\mathrm{T}} \\
{[\mathrm{l} / \mathrm{h} / \mathrm{kg}]}\end{array}$ & $\begin{array}{l}\text { Vdss } \\
{[1 / \mathrm{kg}]}\end{array}$ \\
\hline PIIB $^{a}$ & 26; po & nd & nd & 0 & na & na & na & na \\
\hline 16(R)-F PIIB ${ }^{\mathrm{b}}$ & 100; po & 701 & 0.08 & 1.8 & 445 & 0.6 & na & na \\
\hline 16(R)-F PIIB & $10 ;$ iv & na & na & na & 2408 & 0.1 & 4.2 & 0.7 \\
\hline
\end{tabular}

aData generated following oral administration of PIIB suspended in saline solution containing $0.1 \%$ of polysorbate $80 .{ }^{\text {b RPR }} \mathbf{3 2 5 5 2}$ (Discovery polymorph): iv administration as an aq. soln. containing $30 \% \mathrm{~N}$-methyl pyrrolidone; oral administration alone by gavage as a suspension in $0.5 \%$ methyl cellulose/0.2\% Tween 80 . na: not applicable; nd: not detected.

the subcutaneous route. We assumed that, though relatively metabolically stable, systemic exposure following oral administration was probably not sufficient to ensure a $\mathrm{C}_{\max }$ above the modest MIC of this compound $(0.5 \mathrm{mg} / \mathrm{ml})$ and hence high in vivo activity could not be achieved.

Chemical stability was certainly a complementary factor that contributed to the good in vivo activity of $16(R)$-fluoro PIIB. As shown in Table 4 (entry 4, column 4), this derivative clearly displayed improved chemical stability compared to PIIB (entry 2), between $\mathrm{pH} 4$ and 9 . In spite of its good aqueous stability, its moderate metabolization rate and reasonable permeation properties, PIIB was not very potent in vivo by the oral route probably as a consequence of its

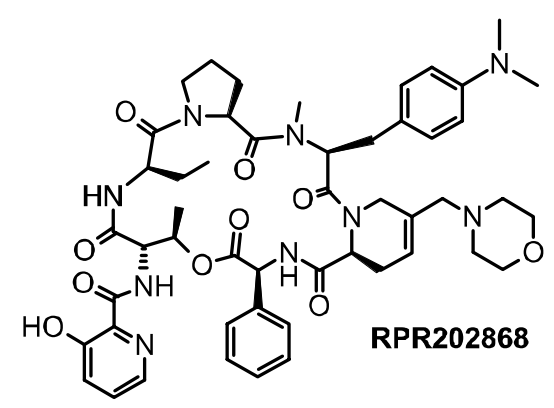

Fig. 3. Structures of both components of the new association RPR202868/RPR132552 $(30 / 70)$ reduced chemical stability under the acidic conditions of the gastro-intestinal tract. For PIIA (entry 1), chemical instability associated to a low aqueous solubility certainly explained its limited oral in vivo potency. Table 4 also suggested that chemical instability and low aqueous solubility (results shown for the $16(R)$ PIIB diol only; entry 3 ) were not operative to understand the moderate oral in vivo potencies of PII diols, since for these derivatives stability and solubility were both outstanding compared to natural PIIs.

Tables 3 and 4 also showed that the poor in vivo activity by the oral route of $16(R)$ fluoro PIIA (entry 7 of Table 3 and entry 5 of Table 4) was mainly a consequence of poor aqueous solubility resulting probably in poor oral absorption. The tendency toward a reduced aqueous solubility when going from the PIIB to the PIIA series was also observed for the natural PIIs and for the $16(R)$-fluoro PIIs. The reduced chemical stability of the $16(R)$-fluoro PIIA compared to the PIIB analogue could also provide an additional explanation to the reduced oral in vivo potency of this derivative. Globally, our results suggested that oral in vivo activity of pristinamycins II resulted from a subtle balance between in vitro antibacterial activity, ADME/PK properties, chemical stability and aqueous solubility.

Overall, introducing a fluorine atom at $\mathrm{C}(16)$ of pristinamycins II had the following consequences: the $16(R)$-fluoro PIIs were against the target ribosome equipotent to their analogous $16(R)$-hydroxy or 16-oxo PIIs; more generally, all $16(R)$-fluoro PIIs displayed improved MICs alone and in combination with PIB against Gram-positive bacteria owing to increased lipophilicity that certainly favored passage through the bacterial membranes; this higher lipophilicity also induced a reduced aqueous solubility and higher metabolization rates but improved oral absorption provided aqueous solubility was not too low. These combined characteristics resulted, in the case of $16(R)$-fluoro PIIB, in enhanced PK properties and hence, in improved in vivo potency by the oral route. Finally, fluorination at C(16) fostered chemical stability by substituting to the very sensitive $\beta$-hydroxy ketone system of natural PIIs a more robust $\beta$-fluoro alcohol that was only sensitive to strongly acidic conditions due to the allylic nature of the remaining alcohol.

Based on its overall properties, RPR132552 was selected as the PII component of the new oral streptogramin. In parallel, we selected RPR202868 as the PI component. The new association RPR202868/RPR132552 (30/70 w/w; Fig. 3 ) displayed an in vitro spectrum of bacteriostatic activity typical of the streptogramin family, including aerobic Grampositive cocci (staphylococci including 
methicillin- $\mathrm{MLS}_{\mathrm{B}}$-resistant strains, streptococci, pneumococci including erythromycin- and/or penicillin-resistant strains, enterococci including vancomycin-resistant strains), certain aerobic Gram-negative bacteria responsible for respiratory tract infections (Moraxella catarrhalis, Neisseria spp. and Haemophilus influenzae, Legionella spp.) and anaerobes.

Its overall in vitro activity was generally close or slightly better than that of Syn$\operatorname{ercid}^{\circledR}$; however, compared to Synercid ${ }^{\circledR}$, the new association demonstrated enhanced potency against aerobic Gram-negative bacteria responsible for respiratory tract infections and against enterococci, including E. faecium. As previously known pristinamycin associations, RPR202868/ RPR132552 (30/70) was rapidly bactericidal against sensitive $S$. aureus, sensitive, erythromycin-resistant Str. pneumoniae and sensitive $H$ influenzae strains tested. $S$. aureus resistant mutants were selected only at low frequency $\left(10^{-9}-10^{-10}\right)$. Moreover, RPR202868/RPR132552 demonstrated potent in vivo activities in all the mouse models of infection studied. This antibacterial profile led to the decision to select RPR202868/RPR132552 (30/70) for clinical development. Overall, the properties of this new association suggest that this streptogramin might be of interest for the treatment of respiratory tract infections in the community and as an oral relay in hospital to treat severe Gram-positive infections.

\section{Conclusion}

We have presented the results of a program aimed at evaluating the impact of fluorination at $\mathrm{C}(16)$ of pristinamycins II. The targeted derivatives were prepared by a sequence involving regioselective silylation of the 14-hydroxy group, DAST-mediated substitution of the free 16-hydroxy group and final unmasking of the 14-hydroxy group. $16(R)$ fluorination was shown to lead to substantially improved antibacterial properties, both in vitro and in vivo by the oral route, as a consequence of retained inhibition of the target ribosome, of higher lipophilicity and of improved chemical stability. Based on these results, we were able to select RPR202868/RPR132552 (30/70 ratio, w/w) as a new oral streptogramin candidate for clinical development following preliminary favorable antibacterial profiling and toxicological results. The overall properties of this association suggest that this new streptogramin might be of interest for the treatment of respiratory tract infections in the community and as an oral relay in hospital to treat severe Gram-positive infections. Detailed anti-bacterial activities of RPR202868/RPR132552 will be reported elsewhere.

\section{Acknowledgements}

We are indebted to all our co-workers (chemistry: Jean-Claude Barrière, Baptiste Ronan, Gilles Dutruc-Rosset, Gérard Puchault, Pascal Desmazeau, Gilles Doerflinger, Guy Pantel; microbiology: Nadine Berthaud, Sylvie Dutka-Malen, Yvette Huet, Dieter Beyer) and technicians who have contributed to this work; we also thank Jean-Marc Paris and Yves Ribeill for their continuous support.

Received: December 18, 2003

[1] a) R. Bax, N. Mullan, J. Verhoef, Int. J. Antimicrob. Agents 2000, 16, 51. b) E.L. Setti, L. Quattrochio, R.G. Micetich. Drugs of the Future 1997, 22, 271. c) D.T.W. Chu, J.J. Plattner, L. Katz, J. Med. Chem. 1996, 39, 3853.

[2] J.M. Paris, J.C. Barrière, C. Smith, P.E. Bost, "The Chemistry of Pristinamycins", in "Recent Progress in the Chemical Synthesis of Antibiotics", Ed. G. Lukacs, M. Ohno, Springer Verlag, Berlin, Heidelberg, New York, 1991, 183.

[3] V. Loncle, A. Casetta, A. Buu-Hoï, N. El Solh, Antimicrob. Agents Chemother. 1993, 37, 2159.

[4] J.C. Barrière, D.H. Bouanchaud, J.M. Paris, O. Rolin, N.V. Harris, C. Smith, J. Antimicrob. Chemother. 1992, 30 (suppl.A): 1.

[5] J.C. Barrière, J.M. Paris, Drugs of the Future 1993, 18 (9), 833.

[6] J.C. Barrière, D. Bouanchaud, J.F. Desnottes, J.M. Paris, Expert Opinion Invest. Drugs 1994, 3 (2), 115.

[7] B. Ronan, E. Bacqué, J.C. Barrière, S. Sablé, Tetrahedron 2003, 59, 2929.

[8] In the poly(U) assay, an artificial mRNA, poly(U), coding only for one amino acid (phenylalanine), is translated and the incorporation of radioactive-labeled phenylalanine into protein (poly[Phe]) is measured. The results are expressed as IC50 values, corresponding to the concentration, expressed in $\mu \mathrm{M}$, at which $50 \%$ of the cell-free poly(Phe) synthesis is blocked. See for more details: 'The ribosome, structure, function and evolution', Ed. W.E. Hill, A. Dahlberg, R.A. Garrett, P.B. Moore, D. Schlessinger, J.R. Warner, American Society for Microbiology Washington, D.C., 1990, chapter 2, 56-70.

[9] The method used to determine MICs was in accordance with the NCCLS recommendations (approved standard M7-A2; National Committee for Laboratory Standards, Villanova, Pa., USA. 1992): twofold dilutions of antibiotic in sterile distilled water were prepared from stock solutions in appropriate solvent and incorporated into appropriate agar media varying with the bacterial species studied. A Denley multipoint inoculator was used to apply spots of about 104 colony-forming units (cfu) of each strain tested to plates. Inoculated plates were incubated at $37^{\circ} \mathrm{C}$ in conditions appropriate to the bacterial species studied. After incubation, the minimal inhibitory concentration (MIC) was defined as the lowest concentration in $\mathrm{mg} / \mathrm{l}$ that completely inhibited the growth of bacteria.
[10] Mice $0 \mathrm{~F} 1$ weighing $20 \pm 2 \mathrm{~g}$ were used for all experiments ( 3 to 6 males +3 to $6 \mathrm{fe}$ males per group). Experimental systemic infections were established by intraperitoneal injection of bacteria diluted so as to obtain an inoculum between 10 and 100 times the lethal dose. Mice were treated orally or subcutaneously by the new associations PIB/PIIs (30/70 w/w). At 7 days post-infection, the effective dose $50 \%$ (ED50) values were calculated as described by G.J. Miraglia, 'Chemotherapy of Infectious Diseases', Ed. H.H. Gadebush, C.R.C. Press, 1976, 1. The ED50 was defined as the dose that protected $50 \%$ of treated mice when all the controls died.

[11] M. Aumercier, S. Boukallab, M.L. Capmau, F. Le Goffic, J. Antimicrob. Chemother. 1986, 39, 9.

[12] In-house results for natural PIIs; for RPR132552, this compound was only metabolized by CYP3A4, with an estimated apparent $\mathrm{Km}$ of $2.5 \mu \mathrm{M}$. 